\title{
Binet Stage
}

National Cancer Institute

\section{Source}

National Cancer Institute. Binet Stage. NCI Thesaurus. Code C141212.

A stage term that refers to the Binet staging system which is used for the staging of chronic lymphocytic leukemia. 